\title{
On the A. Malaris of the Dog
}

\author{
By \\ Masaaki Arai \\ Department of Anatomy, Osaka Dental University, Osaka 540 \\ (Director: Professor Y. Ohta) \\ (with 9 figures in 3 plates) \\ -Received for Publication, October 24, 1977-
}

There have been some works about the malar artery which is observed in the orbit or walls of it in some mammals. The nomenclature, the malar artery, has not been found in textbooks of the human anatomy. Only Zietzschmann (1912) made a suggestion of the presence of the artery, and then a few of investigators have indicated an indefinite branch or an orbital branch of the infraorbital artery which was distributed to the inferior oblique muscle.

The present paper will deal with a detailed observation on the malar artery of the dog, especially the individual difference in one species, discussing the comparative description by previous works.

\section{Materials and Methods}

Forty-five adult dogs (about $5 \mathrm{~kg}$ weight) were used for the observation. Acryl plastic was injected through the common carotid arteries by means of the plastic injection method (Taniguchi, Ohta and Tajiri, 1952, 1955). Forty injected heads of the materials mentioned above were prepared into corrosion specimen of the carotid system. Four were fixed in the formalin solution for dissection, and one was embedded in celloidin, cut serially at $250 \mu \mathrm{m}$ thick, every twentieth section at $20 \mu \mathrm{m}$ thick was stained with hematoxylin and eosin. Fifteen skulls of the dog were used for studying regional relations between the malar artery and the bone structure.

\section{Observations}

The infraorbital artery, $0.9 \sim 2.2 \mathrm{~mm}$, M. $1.26 \mathrm{~mm}$ in diameter, runs forward inferior to its satellite nerve and enters the same named canal with it. When the artery passes forward near the orifice of the canal inferolateral to the origin of the inferior oblique muscle, the 
malar artery, $0.3 \sim 1.0 \mathrm{~mm}$, M. $0.60 \mathrm{~mm}$, leaves the superior wall of the artery (Fig. 1). The malar artery in one case of all examples observed diverges through a common trunk (about $1.4 \mathrm{~mm}$ in length) with the dorsal nasal artery (Fig. 2).

The malar artery ascends lateral to the infraorbital nerve, giving twigs to it and its surroundings, up to the superior wall of the canal, makes a superoposterior curve along the wall backward as far as the orifice of the canal and reaches, after bending medialward, the superior margin of the origin of the inferior oblique muscle. When the origin of the artery is located near or anterior to the origin of the muscle in 34 cases, the above-mentioned curve becomes stronger. When the origin is located posterior to the origin of the muscle in 46 cases, it ascends straightly up to above the orifice of the canal and runs medialward superior to the muscle after bending medialward in the medial side of the orifice. In some cases an incisure or a small foramen is formed by this artery on the surface of the maxilla or lacrimal bone around the superior margin of the orifice (Fig. 3). In other cases the artery makes a loop near the margin and passes posteromedially.

When the artery runs lateral to and dorsal to the infraorbital nerve, it gives off the inferior oblique muscular branch.

The main stem of the malar artery runs superomedially on the orbital surface of the lacrimal bone inferior to the periorbital fat (Miller, 1964) and reaches the lateral end of the orbital orifice of the nasolacrimal canal, giving off periosteal branches. The artery and the branches at this point are situated outside the periorbita and do not penetrate it into the orbital contents in any case. Then the artery crosses the orifice of the nasolacrimal canal, that is, lateral to the inferior end of the lacrimal sac, sending off the lacrimal sac branch. The artery finally bends upward and terminates stellately into two to five after passing through the lateral portion of a gap between the orbital septum of the lower eyelid and the medial palpebral ligament, lateral to the zygomaticolacrimal suture beneath the medial canthus. Some of them run medially as the nasal radical branches and the others laterally as the inferior palpebral branches.

Branches of the malar artery are as follows:

1. Branch running along the infraorbital nerve (Fig. 1)

The branch, $0.02 \sim 0.2 \mathrm{~mm}$, M. $0.11 \mathrm{~mm}$ in diameter, of which one was observed in 6 cases and two in 74 cases, diverges from the malar artery when it ascends lateral to the infraorbital nerve. It gives twigs to the nerve and its surroundings, and some of them are distributed to the lateral wall of the infraorbital canal, anastomosing with the middle superior alveolar artery (Suzuki, 1977) arising from the infraorbital artery, proximal to the orifice of the infraorbital canal (Fig. 4). 
2. Inferior oblique muscular branch (Fig. 1)

The branch, $0.1 \sim 1.0 \mathrm{~mm}$, M. $0.24 \mathrm{~mm}$, is observed in 78 cases of all 80 examples; one in 68 cases and two in 10 cases. Various features in the arising and course of it are influenced by arising features of the parent artery. It runs posteromedially and penetrates the periorbita into the orbit after giving small twigs to the periosteum and the periorbital fat surrounding the orifice of the infraorbital canal. In cases in which two branches are seen, the distal vessel penetrates it nearer the venter of the muscle than the proximal one does. The branch in the orbit supplies postero-supero-laterally the muscle from its origin through its insertion and anastomoses with the same named branch of the ventral muscular branch (Miller) of the orbital artery.

The branch in two cases, arising directly from the superior wall of the infraorbital (in contact with the origin of the malar in one case of the two), penetrates the periorbita near the origin of the muscle into the orbit and bends backward to supply it (Fig. 5).

3. Periosteal branch (Fig. 1)

The branches, $0.09 \sim 0.3 \mathrm{~mm}$, M. $0.18 \mathrm{mn}, 2-4$ in number, arise from the malar on the orbital surface of the lacrimal or zygomatic bone, and are distributed to the periosteum, periorbital fat and bone. In 66 cases, the branch, being rather thick, runs forward in the bone far to the nasolacrimal canal of the maxilla and supplies it as the nasolacrimal branch which anastomoses with the branch to the lateral wall of the maxillary recessus (Ozaki, 1968). Twigs of it supply the mucosa of the recessus.

4. Lacrimal sac branch (Figs. 6, 7 and 8)

The branches, $0.1 \sim 0.3 \mathrm{~mm}$, M. $0.19 \mathrm{~mm}, 1-4$ in number, arise from the malar, lateral to the inferior end of the lacrimal sac and close to the orifice of the nasolacrimal canal, or arise from the malar before it leaves the orbit (Fig. 6), and an additional branch arises from the nasal radical branch in 64 cases (Fig. 7).

The branch arising at the inferior end of the sac divides into the superior and inferior. The former ascends supplying the posterolateral wall of the sac, the lacrimal canaliculi and part of the upper eyelid. In two cases the branch is well-developed and becomes the superior palpebral branch (about $0.3 \mathrm{~mm}$ in diameter, Fig. 8). The latter, the nasolacrimal branch, runs inferoanteriorly and anastomoses with the same named branch of the periosteal branch. In 14 cases the latter is not observed and the canal is supplied by the periosteal branch.

The branch arising before the malar leaves the orbit (Fig. 6) and the additional branch (Fig. 8) are distributed to the anterior wall of the sac and the lacrimal canaliculi.

5. Nasal radical branch (Figs. 1,8 and 9)

The branch, $0.2 \sim 0.5 \mathrm{~mm}$, M. $0.38 \mathrm{~mm}$ in diameter, diverges from the malar or in common with the inferior palpebral branch, and divides 
into a branch to the antero-infero-medial and a branch to the superomedial. The former spreads into small twigs which are distributed to the nasal dorsum. They, well-developed in 4 cases, participate in the formation of the rete dorsale nasi (Hanai, 1964), and communicate with the nasal dorsal branch (Ryumon, 1970) of the lateral superior palpebral branch of the superficial temporal medialward, and with the nasal dorsal artery (Hanai) of the infraorbital and the posterior superior labial (Hanai) of the facial downward. The latter spreads into two or three twigs which run anteromedially from the medial canthus to supply the nasal radix, anastomosing with the nasal dorsal branch (Ryumon) of the lateral superior palpebral of the superficial temporal which descends from the upper lid site.

6. Inferior palpebral branch

The branch ramifies into the palpebral marginal branch, the ocular orbicular muscular branch and the orbital marginal branch. They leave the malar independently or through a common trunk between the former and the middle or between the middle and the latter, or in common with the nasal radical branch.

a) Palpebral marginal branch (Figs. 8 and 9)

The branch, $0.3 \sim 0.6 \mathrm{~mm}$, M. $0.57 \mathrm{~mm}$, runs lateralward from the medial canthus behind the ocular muscle, about $1 \mathrm{~mm}$ inferior to the inferior palpebral margin tortuously, and forms an arterial arch by communicating with the lateral inferior palpebral branch (Ryumon) of the superficial temporal or lacrimal, which is distributed to the lower lid medially. From the arch, lots of twigs sprout toward the inferior palpebral margin.

b) Ocular orbicular muscular branch (Fig. 9)

The branch, $0.1 \sim 0.3 \mathrm{~mm}$, M. $0.22 \mathrm{~mm}$, passes lateralward in the ocular orbicular muscle and is distributed to the skin and the medial two-thirds of the muscle.

c) Orbital marginal branch (Fig. 9)

The branch, $0.2 \sim 0.4 \mathrm{~mm}$, M. $0.29 \mathrm{~mm}$, runs lateralward on the periosteum along the inferior margin of the orbit and forms an arterial arch by communicating with the inferior palpebral branch of the superficial temporal. Inferior twigs from the arch communicate with peripheries of the posterior superior labial (Hanai) of the facial and with peripheries of the nasal dorsal branch on the facial surface of the maxilla. Superior twigs of it communicate with peripheries of the ocular orbicular muscular branches and twigs of the arterial arch in the palpebral margin. 


\section{Discussion}

Description on the malar artery of the dog by Ellenberger et al. (1891) and Miller (1964) were not in detail but accurate. They stated that the malar arose from the infraorbital, giving small twigs to the inferior oblique muscle, ran toward the medial canthus superficial to the periorbita far to the lower lid. Anastomoses with the infraorbital in the lower lid were described by Ellenberger et al., and with the inferior palpebral and the transverse facial by Miller, who also stated the malar was distributed to the nasolacrimal canal. The present author, however, did not observe any twigs supplying the lower lid of the malar by communicating with the transverse facial. Ikoma (1955) in the dog stated that the infraorbital gave off the inferior oblique muscular branch. This might correspond to the malar described in this paper, but the branch, supplying the muscle, arising from the angular artery of the eye by Ikoma was not seen by the present author.

Ellenberger et al. (1943) and Nickel et al. (1976) made a description of the malar artery in domestic animals; arising from the maxillary in the pig and ruminants, and from the infraorbital in the dog and cat. Masui (1957) and Kato (1973) also stated that the malar of the cattle and pig arose from the maxillary artery. Crough et al. (1969) and McClure et al. (1973) described that in the cat the angular artery diverged from the infraorbital before it entered the maxillary foramen. Sisson and Grossmann (1956) stated that the malar artery of the horse left the infraorbital and gave small twigs to the inferior oblique muscle and the lacrimal sac, anastomosing with the $r$. angularis oculi in the lower lid, and that the malar of the cattle was large, left the infraorbital, then, emerged from the orbit near the medial angle and was continued as the dorsal nasal, giving off branches which took the place of the angular artery of the eye. Schmidt (1910) made a detailed observation that the malar of the cattle arose from the internal maxillary, supplied its twigs to the m. obliquus oculi, the orbital fat, the periorbita and that its terminal stem ran on the nasal dorsum as the a. dorsalis nasi. Davis et al. (1943), comparing with the description of Hürlimann, made detailed observations on the angular artery of the cat as follows: The angular artery, the malar of Hürlimann in the cat, which in man arose from the external maxillary, arose from the infraorbital, passed forward immediately below the eyeball, but outside the periorbita and bifurcated into the branch to the lacrimal sac and its vicinity and the a. dorsalis nasi. The malar artery of the dog, however, arose from the infraorbital, and the a. dorsalis nasi of these workers has been described as the nasal radical branch in the present paper, while the dorsal nasal artery was a branch of the infraorbital.

In the cat Hürlimann (1912) described in detail the malar artery 
arising from the dorsal wall of the infraorbital, lateral to the origin of the inferior oblique muscle, ran across the infraorbital nerve oromedially and arched dorsally at the origin of muscle and the nasal dorsal artery left the convex of the above-mentioned arch, and was distributed to the insertion of the muscle and extraorbital fat tissue, then the a. palpebrae tertiae was given off. Features of the arising, passage and the distribution of the malar artery were similar to them in the dog, but the nasal dorsal artery arising in common with the malar of the dog was seen in only one case of all the examples observed. This artery and the palpebrae tertiae generally did not diverge from the malar in the dog, Zietzschmann (1912) in mammals stated that the malar artery of some mammals was distributed to the ventral oblique muscle, the lids, the lacrimal canal and the third eyelid. The present author did not observe such an artery as supplying the third lid in the dog. Zietzschmann described generally terminal branches of the malar were the superior and inferior nasal palpebral arteries. This terminal division of the dog was observed in only two cases of all the examples observed in the present paper, but the superior nasal palpebral artery in most cases, being not developed, terminated only as the lacrimal sac branch. While, the inferior nasal palpebral artery came into the lower lid as the continuation of the malar artery. It made an arterial arch in the lower lid by communicating with the palpebral branch of the superficial temporal artery in the dog and cat.

In the crab-eating monkey Matsukawa (1969) made the description that the r. nasalis lacrimalis of the infraorbital gave small twigs to the inferior oblique muscle, and was distributed to the nasolacrimal canal through the maxillolacrimal suture. The ramus might correspond to the malar of the dog described in this paper.

In textbooks of the human anatomy there has not been the name "malar artery", but some descriptions have been seen relating to vessels which were distributed to the floor of the orbit and its vicinity. Kopsch (1955) described in Rauber's textbook that the infraorbital artery sent small twigs in the same named canal to muscles of the eye ball located in the floor of the orbit. Sicher (1965) also stated that such twigs supplied the inferior rectus and oblique muscles and the lower lid. In the textbook of Gray's Anatomy these twigs were called the orbital branch which assisted in supplying the inferior rectus and oblique and the lacrimal sac. Kaneko (1976) and Hirasawa and Okamoto (1976) described that the infraorbital gave off the orbital branch which was distributed to the floor of the orbit. Kamijo (1966) called it the ophthalmic branch and made a similar description to them. After all the present author has considered these branches described by these scholars might correspond to the malar artery of the dog. 


\section{Conclusions}

1. Investigation on the malar artery of the dog was made by means of the acryl plastic injection method.

2. The malar artery arose from the infraorbital inferolateral to the origin on the inferior oblique muscle, but very rarely in common with the dorsal nasal artery.

3. Near the origin of the artery, it gave off a branch running along the infraorbital nerve which supplied the nerve and the periosteum of the medial surface of the zygomatic bone anastomosing with peripheries of the middle superior alveolar artery. When the malar ran around the inferior oblique muscle lateralward to upward, it gave off the inferior oblique muscular branch which was the only one penetrating into the orbital contents.

4. The malar then curved above the inferior oblique muscle medialward and passed superomedially outside the periorbita on the lacrimal bone. Here it gave off the periosteal branches which supplied the periorbital fat and bone, and often became the nasolacrimal branch running in the maxilla.

5. The malar gave off the lacrimal sac branch at the inferolateral end of the sac. The branch divided into the superior and inferior. The former ran upward behind the sac to supply it and lacrimal canaliculi and sometimes developed into the superior palpebral branch. The latter was the nasolacrimal branch.

6. The malar, being situated outside the periorbita and not in the orbital contents, ramified stellately into the nasal radical branches and the inferior palpebral branch at the inferomedial end of the lower eye lid. The nasal radical branches supplied the nasal dorsum, anastomosing with the same named branch of the lateral superior palpebral artery of the superficial temporal, with peripheries of the infraorbital and the posterior superior labial of the facial artery.

The inferior palpebral branch ramified into the palpebral marginal branch, the ocular orbicular muscular branch and the orbital marginal branch. The first passed laterally near the inferior palpebral margin and communicated with the lateral inferior palpebral branch of the superficial temporal and of the lacrimal artery. The middle supplied the medial two-thirds of the ocular orbicular in the lower eyelid. The last passed laterally along the inferior margin of the orbit and formed an arterial arch by anastomosing with the inferior palpebral branch of the superficial temporal and the posterior superior labial of the facial artery.

The author wishes to express his thanks to Professor Y. Ohta, Assistant Professor T. Tokioka and staff members of the Department of Anatomy for guidance and encouragement showed to him. 


\section{References}

1) Crough, J. E. \& M. B. Lackey: Text-atlas of cat anatomy. Lea \& Febiger, Phila., 1969.

2) Davis, D. D. and H. E. Story: The carotid circulation in the domestic cat. Zool. Series, Field Museum of Nat. History. 28, 1943.

3) Ellenberger, W. \& H. Baum: Systematische und topographische Anatomie des Hundes. Paul Parey, Berlin, 1891.

4) Ellenberger, W. \& H. Baum: Handbuch d. vergleichenden Anatomie d. Haustiere. 18 Aufl., Springer-Verlag, Berlin, 1943.

5) Hanai, H.: Stereological studies on several ducts and vessels by injection method of acrylic resin. XIII. Arterial distribution of the upper lip in some mammals. Okajimas Fol. anat. jap., $40: 81-128,1964$.

6) Hirasawa, K. \& M. Okamoto: Anatomy. II., 10th ed., Kanehara Co., Tokyo, 1976. (in Japanese)

7) Hürlimann, R. : Die arteriellen Kopfgefässe der Katze. Intern. Mschr. Anat., 29 : 371-442, 1912.

8) Ikoma, K. : Studies on the vascularisation inside of the orbit of mammalia. Chapter 1: In Dogs. Kurume Igakuzasshi, $18: 1190-1229$, 1955. (in Japanese)

9) Kamijo, Y.: Oral anatomy, III. Angiology, 1st ed., Anatom co., Tokyo, 1966. (in Japanese)

10) Kaneko, U.: Human anatomy of Japanese. I, II \& III., 12th ed., Nanzando, Tokyo. 1976. (in Japanese)

11) Kato, K.: Atlas of the comparative anatomy of the domestic animals. I \& II., Yokendo, Tokyo, 1973. (in Japanese)

12) Kopsch, F.R.: Lehrbuch und Atlas der Anatomie des Menschen. Georg Thieme, Stuttgart, 1955.

13) Masui, K.: Comparative anatomy of the domestic animals. I \& II., 8th ed., Yokendo, Tokyo, 1957. (in Japanese)

14) Matsukawa, M., A. Ryumon, H. Furuhara \& S. Masuda : Stereological studies on several ducts and vessels by injection method of acrylic resin. XXII. On the superficial temporal artery of Macacus cynomolgos. Okajimas Fol. anat. jap., 45 : 267-278, 1969.

15) McClure, R.C., M. J. Dallman and P.D. Garrett: Cat anatomy. Lea \& Febriger, Phila., 1973.

16) Miller, M.E., G.C. Christensen \& H. E. Evans: Anatomy of the dog. W. B. Saunders Co., Phila., 1964.

17) Nickel, R., A. Schummer \& E. Seiferle: Lehrbuch d. Anatomie d. Haustiere. Bd. III, Paul Parey, Berlin, 1976.

18) Ozaki, A. : Stereological studies on several ducts and vessels by injection method of acrylic resin. XVII. On the sphenopalatine artery in some mammals. Okajimas Fol. anat. jap., $44: 301-336,1968$.

19) Ryumon, A. : Stereological studies of several ducts and vessels by injection method of acrylic resin. XXVII. On the superficial temporal artery in some mammals. Okajimas Fol. anat. jap., 47 : 353-374, 1976.

20) Schmidt, K.: Die arteriellen Kopfgefässe des Rindes. Internat. Monatschr. f. Anat. und Physiol., 27, 1910.

21) Sicher, H. : Oral Anatomy. C. V. Mosby Co., St. Louis, 1965.

22) Sisson, S. and J. D. Grossman.: Anatomy of the domestic animals. 4th ed., W. B. Saunders Co., Phila., 1956.

23) Suzuki, S.: On the anterior, the middle and the posterior superior alveolar arteries of the dog. Okajimas Fol. anat. jap., $54: 289-316,1977$. 
24) Taniguchi, Y., Y. Ohta and S. Tajiri: New improved method for injection of acrylic resin. Okajimas Fol. anat. jap., 24 : 259-267, 1952.

25) Taniguchi, Y., Y. Ohta, S. Tajiri, H. Okano and H. Hanai: Supplement to new improved method for injection of acrylic resin. Okajimas Fol. anat. jap., 27 : 401406, 1955.

26) Warwick, R. \& P. L. Williams: Gray's anatomy. 35th ed., Longman, London, 1973.

27) Zietzschmann, V., : Zur Vaskularisation des Bulbus und seiner Nebenorgane. Anat. Anz., Ergänzungsheft z. $41:$ 107-118, 1912. 


\title{
Explanation of figures
}

\section{Key to abbreviations}

\author{
F Palpebral fissure \\ LS Lacrimal sac \\ M Inferior oblique muscle \\ $\mathrm{S}$ Maxillary sinus \\ LC Lacrimal canal

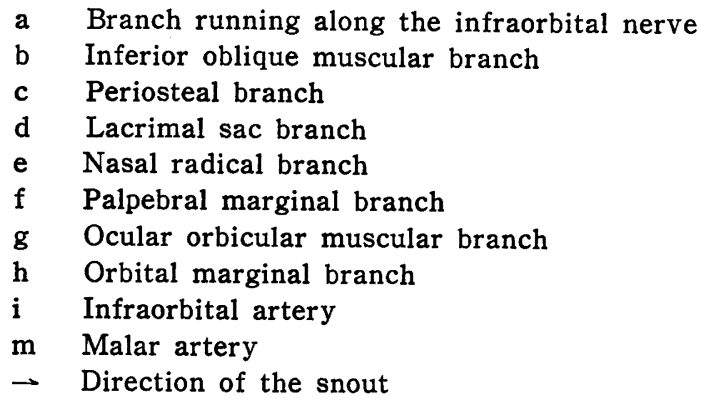

\section{Plate I}

Fig. 1. Origin and the whole distributing feature of the malar artery of the left side. Higher magnification of the inset of the lateral view of the buccal area. The infraorbital canal, the infraorbital nerve $(O)$, the nasolacrimal canal and the maxillary sinus are shown by removal of the lateral part of the maxilla and the zygomatic bone. 

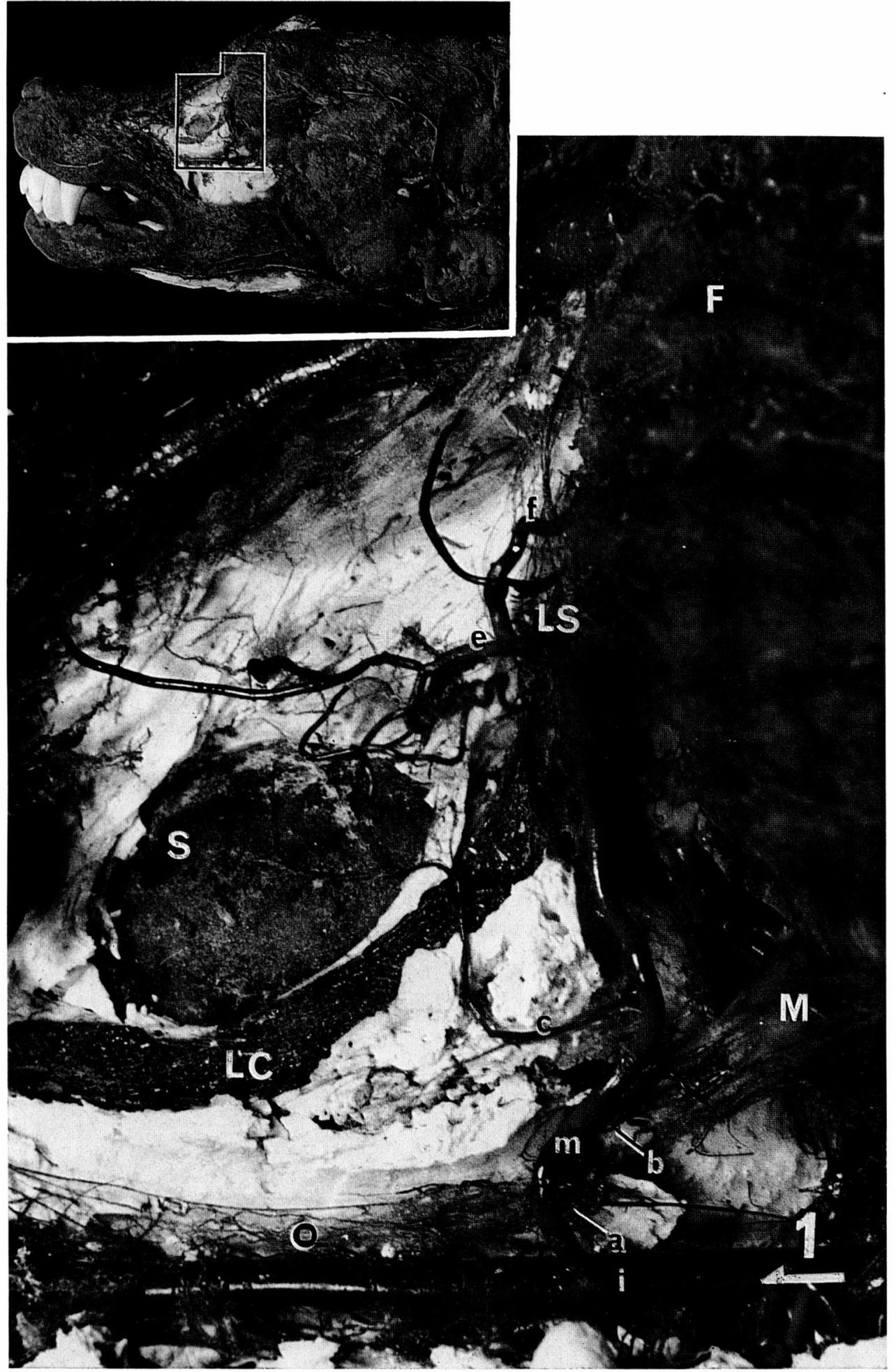

M. Arai 


\section{Plate II}

Fig. 2. The lateral view of the buccal area of the left side. The infraorbital artery and the origin of the malar artery which arises through a common trunk $(\swarrow)$ with the dorsal nasal artery $(\bigcirc)$, are shown by removal of the lateral part of the maxilla and the zygomatic bone.

Fig. 3. The posterior view of the anterior wall of the orbital fossa of the right side of the dog skull. A small foramen $(\leftarrow)$, situated above the superior margin of a large orifice of the infraorbital foramen, through which the malar artery passes. The posterior palatine (1), the sphenopalatine (2) foramen and the fossa (3) for lacrimal sac.

Fig. 4. The medial view of the maxillary tuber of the left side. Branches of the infraorbital artery anastomose $(\swarrow)$ with branches of the middle superior alveolar artery $(O)$ arising from the infraorbital artery proximal to the orifice of the same named canal.

Fig. 5. The lateral and slightly posterior view of the anterior wall of the orbital fossa of the right side. The inferior oblique muscular branch arises directly from the superior wall of the infraorbital artery proximal to the origin of the malar artery.

Fig. 6. The posterior view of the anterior wall of the orbital fossa of the left side. One lacrimal sac branch $(O)$ arises at the inferior end of the sac and the other $(x)$ arises before the malar leaves the orbital fossa, and they supply the sac anastomosing with each other. 

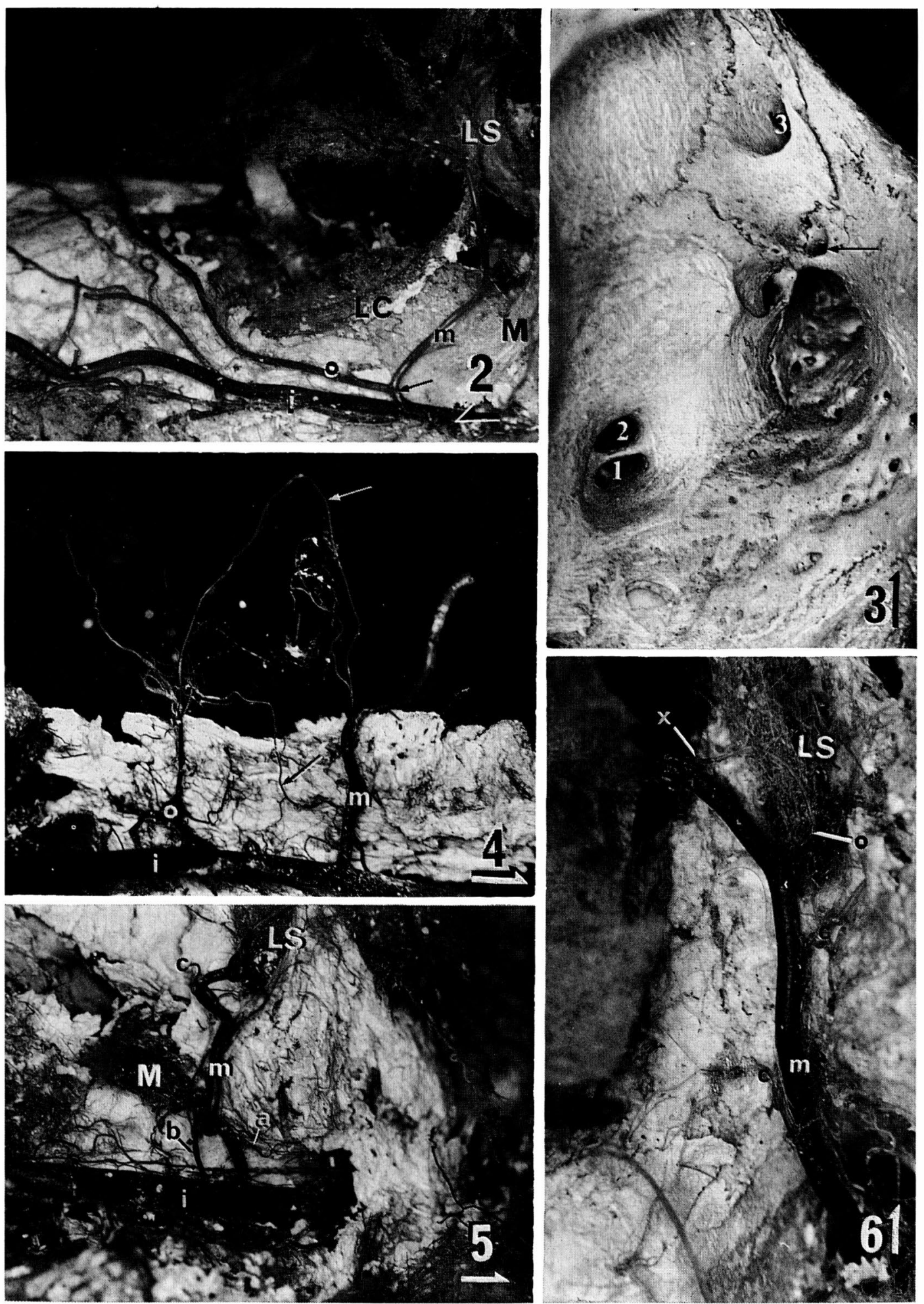

M. Arai 


\section{Plate III}

Fig. 7. The anterolateral view of the medial canthus of the left side. The lacrimal sac and the superior and inferior lacrimal canaliculi are shown by removal of the vascular pattern of the skin. The lacrimal sac branch arising from the nasal radical branch is distributed to the canaliculi (arrows) and the anterior wall of the sac.

Fig. 8. The anterior view of the anterior wall of the orbital fossa and the eyelids of the right side. In this case a thick lacrimal sac branch arising at the inferolateral end of the sac develops into the superior palpebral branch $(\downarrow)$.

Fig. 9. The anterolateral view of the palpebrae of the left side. The nasal radical branches participate in the formation of the nasal dorsal rete, and anastomose $(\rightarrow)$ with the nasal dorsal branch of the lateral superior palpebral branch of the superficial temporal artery $(O)$. The orbital marginal, the inferior palpebral and the ocular orbicular muscular branches of the inferior palpebral branch, are seen, and the first one anastomoses $(*)$ with the inferior palpebral branch of the superficial temporal artery. 
Plate III
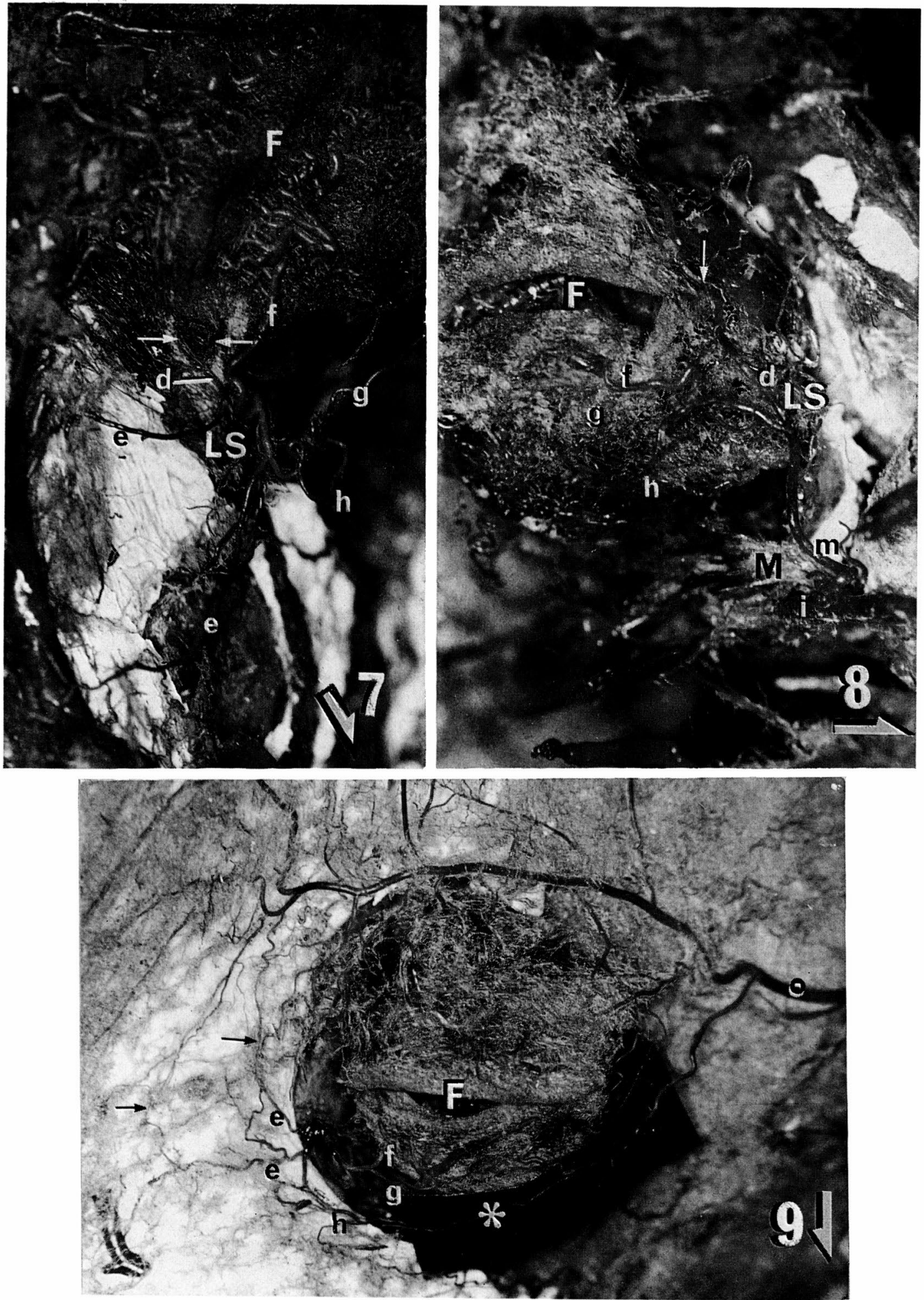

M. Arai 